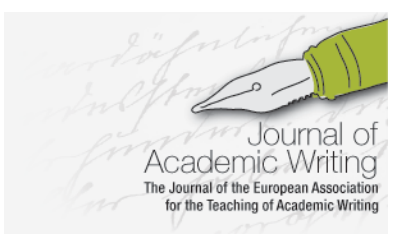

Journal of Academic Writing

Vol. 10 No 1 WINTER 2020, pages 14-24 https://doi.org/10.18552/joaw.v10i1.583

\title{
Centralised Supports for Writing in Higher Education and Their Applicability to Research, Teaching and Learning Contexts
}

\author{
Matthew Fogarty \\ Maynooth University, Ireland
}

\begin{abstract}
In 2018, as part of an EU COST Action (COST Action 15221 - www.werelate.eu), 43 academics, based at various higher education institutions in Europe, were asked about existing and desirable centralised support for writing, research, teaching and learning. This article draws on the academics' responses. It uses that data to demonstrate the ways in which the learnercentred approach, typically adopted by writing centres, might function as a blueprint for a blended centralised support model for these four strands of higher education. In order to explore this idea, the article examines the reported support for research, as the data suggest that the majority of the centralised supports that currently exist at these institutions are designed primarily to support research. The study unpicks the mechanisms and approaches that are designed to ensure that research can be supported; it identifies what is effective in terms of supporting staff as researchers. From there, turning to the existing and desirable supports for writing, teaching and learning, I argue that, using a learner-centred writing centre model as inspiration, the structures which are currently in place to effectively support research can be modified and repurposed to more effectively support writing, teaching, and learning in higher education.
\end{abstract}

\section{Introduction}

From the European vantage point, it might appear that the learner-centred writing centre model has not changed much over the years. However, the ethos of the contemporary writing centre bears little resemblance to the diagnostic approach favoured in the early twentieth-century, USbased writing "laboratories" and "clinics" from which it evolved. Although Lerner (2003) points out that some of these laboratories and clinics adopted a student-centred approach, this ethos has become the standard for best practice in writing centres today (Farrell et al. 2015). It is primarily manifested in one-to-one appointments with writing centre tutors, which remain the writing centre's principal stock-in-trade. This learner-centred model is designed around responding to students' needs, in alignment with broader pedagogical considerations. Because these models, and the centres themselves, are situated in complex institutional contexts, writing centre offerings continue to develop as is reflected in the diverse range of services and supports typically offered by contemporary writing centres. Designed, in part, to foster collaborative learning and build connections across various units and departments, these services typically include:

- Discipline-specific work with individual departments

- Referral to other services/supports on campus

- Access to materials, writing resources, and handouts

- Web-based learning materials, including self-diagnostic tests

- Interdisciplinary and collaborative workshops, for example, working with Library, Access, Assistive Technologies, individual or groups of academic departments to facilitate relevant workshops for writers 
- Scheduled topic-specific sessions ('hot topics')

- The provision of writers' retreats/writers' groups (Farrell et al., 2015, p. 12)

Girgensohn (2018) notes that their experience as collaborative learning practitioners serves writing centre directors well. Indeed, the situation of the work of writing centres between teaching, learning, research and writing necessitates a collaborative approach (Fogarty et al., 2019). In this article, I explore how the support mechanisms typically offered by the university writing centre might be further developed to establish similarly effective support mechanisms for teaching, learning, and research in higher education.

The study draws on data gathered in the exploratory stages of EU COST Action 15221, WeReLaTe: Advancing effective institutional models towards cohesive teaching, learning, research and writing development, which was launched in October, 2016. That data was considered as part of a Short Term Scientific Mission (STSM), funded by the COST Action with a view to addressing one of the Action's research objectives. This article has evolved out of the work completed during that STSM. The Action's primary purpose is to explore how effective synergies could be established between research, writing, teaching and learning in higher education. My objective in examining the data gathered by this Action was to identify concordant and discordant patterns and themes regarding supports for the teaching, learning, research and writing strands of higher education. More specifically, I wanted to explore how the mechanisms used to effectively support research could be modified and repurposed to more effectively support writing, teaching, and learning in higher education, and vice versa. For this reason, I primarily focused on responses to two open-ended questions that appeared in the COST Action data:

1. Please describe the centralised support that exists for teaching, learning, research and writing in your institution. In addition to describing what exists, please comment on the interoperability of the supports - how do they connect with one and other? You should aim to write maximum 300 words.

2. Please free write for a half hour to finish this prompt: 'If I were President/Provost/Chancellor/Rector/Leader (number one decision maker) of my institution, how would I best (in an ideal world) support teaching, learning, research and writing in my institution?

The conclusions drawn in this article stem directly from the aggregate responses to these questions (from now on called the existing models (1) and desirable models (2) data for expediency). I further argue that the writing centre appears primed to evolve once more where the organisational functions it typically performs could be used as a blueprint for synergising supports for research, writing, teaching and learning in higher education.

\section{Methods}

The COST Action set two primary goals with a view to determining effective synergies across support for research, writing, teaching, and learning in higher education:

1. Classifying, as frontier taxonomies, the common ground in terms of shared purposes, processes, knowledge, values, and skills among centralised institutional supports for research, writing, teaching, and learning in order to capitalise on their synergies.

2. Offering the most advantageous models and practices for supporting these four areas that are mindful of the availability of new technologies and assessments, and that prompt a reworking of current institutional supports which will be valuable and farreaching. (COST Action 15221, 2016)

With these objectives in mind, 43 of the Action's Management Committee members (MCs), who are all based at higher education institutions around Europe, took part in a survey comprised 
of 8 Likert questions and the two open-ended questions that yielded the existing models and desirable models data. ${ }^{1}$ During my STSM, I analysed the responses using phenomenography. As Larsson and Holmström (2007) explain, this qualitative method is designed to identify, and distinguish between, the different ways in which different people, or groups of people, experience and understand a particular phenomenon; in this regard, it differs from 'phenomenology,' which seeks to clarify the meaning, or indeed the structure, of a particular phenomenon. Phenomenography works well whenever a theory is not available to explain or understand all of the processes described in the data, or when a number of fragmented theories are present, which by themselves do not address potentially important variables that emerge from the aggregate of perspectives recorded in the data. As my objective was to identify how the existing and desirable supports for research might, for example, be adapted to establish effective mechanisms to support writing, teaching and learning, and vice versa, the phenomenographic method seemed the logical choice.

As outlined by Table 1, the analysis of the data that was undertaken followed the seven-step phenomenographic method set out by Larsson and Holmström (2007):

Table 1

Phenomenographic Steps and Actions Undertaken

\begin{tabular}{ll}
\hline Phenomenographic Steps $\quad$ Actions Undertaken \\
\hline
\end{tabular}

1. Read the whole text.

2. Read again and mark where the interviewee gave answers to the main interview questions.

3. In these passages, look for what the focus of the interviewee's attention is and how they describe their way of working. Make a preliminary description of each interviewee's predominant way of understanding the work.

4. Group the descriptions into categories, based on similarities and differences. Formulate categories of description.

5. Look for non-dominant ways of understanding.
The responses to the 8 Likert questions and the open-ended questions were read in their entirety to contextualise the data.

The responses to the open-ended questions were then read for a second time. All references to the four principal phenomena (teaching, learning, research and writing) were colour-coded.

This focus on the respondents' experiences of the four principal phenomena yielded a number of predominant patterns, both in the existing models data and the desirable models data.

The predominant experiences described in the existing models data were categorised as functional supports, dysfunctional supports, formal supports, and informal supports.

The predominant experiences described in the desirable models data were categorised as physical visibility, online visibility, training, communication, personnel, and management structure.

The patterns that emerged from the existing models data indicated that the formal and functional supports were predominantly implemented to support research.

\footnotetext{
${ }^{1}$ Members of the Action's Management Committee gave their permission to colleagues to use Action gathered data and associated outputs, in Action related publications as long as the publication includes the agreed acknowledgement.
} 
Phenomenographic Steps

6. Find a structure in the outcome space.

\section{Actions Undertaken}

Existing research supports were typically implemented in instances where the university reported having clear objectives and/or specific requirements. When comparable formal and functional supports were put in place to support teaching and learning, it was usually because the university reported having similarly clear objectives and/or specific requirements.

The data sets also revealed a variety of factors, such as writing skills, which were crucial to ensuring that these clear research objectives could be achieved. Although some universities did recognise the importance of these additional factors, these skills were often imparted by altruistic colleagues, i.e. informal supports. There were also universities that provided supports in theory, but not in practice, or simply did so ineffectively, i.e. dysfunctional supports.

7. Assign a metaphor to each category of description.
The clear objectives and specific requirements described in the existing models data were labelled as open targets. The additional factors that the MCs identified as keys to achieving these open targets were labelled as lateral targets. The supports that existed at some universities to address these lateral targets, but were either dysfunctional or not available to all as they were only offered informally, were labelled as hidden targets. This label is also used to refer to instances where universities do not make any attempt to address lateral targets.

\section{Results}

The discovery of the open, lateral, and hidden targets outlined in Table 1 established the key components of the structure that appeared in the outcome space. In this section, I provide a detailed description of how these components emerged from the existing models data. ${ }^{2}$ Turning to the desirable models data, I further demonstrate how MCs identified a blended centralised supports model as the most effective way to achieve these open, lateral, and hidden targets.

\section{Open targets}

The existing models data indicated that the most formal and functional research supports were typically implemented to secure research funding and to ensure that these funds were safely managed. One respondent observed that the research office at their institution "encourages

\footnotetext{
${ }^{2}$ It is beyond the scope of this article to provide an overview of the existing models data as my primary objective is to explore how the structures which are currently in place to effectively support research can be modified and repurposed to more effectively support writing, teaching, and learning in higher education. See Farrell (2018) for a comprehensive thematic analysis and mapping of this data.
} 
research by providing support through internal grants and scholarships for research purposes" and "is responsible for financial and administrative monitoring of [the successful] research proposals." Despite providing a comprehensive description of this institution's research office structure and the various functions it performs, this respondent did not make any reference to teaching, learning, or writing, even though the question specifically asked the respondents to describe the centralised supports that exist for teaching, learning, research and writing at their respective institutions. This could imply that there are no centralised supports for teaching, learning and writing at this MC's institution, which provides a stark contrast to carefully thoughtout measures that have been put in place to support research at this university, or that the respondent does not value these three strands of higher education to the same extent that they value research. A similar model, albeit on a smaller scale, was described by another participant as the primary means by which the sparse research funding that was available at their university was managed:

Research is conducted individually by teaching staff in their respective fields. The centralised support is provided through the budget...via the [Name of Government Department responsible for Higher Education] in the form of funds for research and publishing. However, since the budget is usually tight, usually only a few individuals have managed to take advantage of these resources.

Another respondent described a comparable mechanism to support research at their university:

Research and writing are under the responsibility of the [Name of this role of responsibility]. His/her office monitors the publishing activities. The University dedicates annually some funds that can be used for attending or participating at a congress (approx. €700 per person per year). Based on a researcher's publishing activity and research quality, the [Name of Government Department responsible for Higher Education] can allocate extra funds for research. Furthermore, the [Title of senior leader] follows the researchers' mobility within the EURAXESS programme and cooperates with other research institutions within the country and abroad.

This is not an exhaustive account of the structures that are used in the participants' universities to ensure that research funds are secured and effectively managed. However, this particular open target, labelled as such because the acquisition and effective management of funding are clearly delineated instutional objectives, was the one that appeared most frequently in the existing models data.

The data also contain several instances when comparable structures are implemented with a view to hitting other types of open targets. For example, the participant who provided the detailed description of their university's Research Office and of the functions it performs noted that this body also "takes care of all ethic issues concerning the studies." In the second model referred to above, the university has a parallel office, in addition to the research office, which primarily focuses on students, programmes and collaboration. That "student" office supports "the activities related to the organization of teaching and students." Their office is in charge of developing "new study programmes and syllabus, following the quality of students' life while on campus, resolving staff matters, and promoting the quality system at the university." This implementation of teaching and learning structures to ensure that quality standards are maintained and national accreditations are received is another recurring theme in the existing models data. Another respondent noted that:

In the case of teaching and learning, there is clear centralised support by the state, which is basically reflecting the centralised higher education system of the top-down hierarchy, 'Minister-University-Faculty-Teacher-Student'. Actually, the contents of the courses, as well as teaching and learning methods, are determined in detail within the accreditation of individual study programs at the Ministry level.

Another participant described a "centralised University Quality Assurance Service, led by the [Senior Leader] for Teaching and composed by administration staff, teachers and student representatives." This respondent also described "a centralised Language Centre [that] offers 
institution-wide support for students and staff" and an "International Relation office [that] fosters internationalisation of teaching through dedicated consultancies for Erasmus+ grants and for student and staff mobility." Again, this represents a small sample of the structures that are put in place in various European universities when there are clear objectives and/or specific requirements. Indeed, the emphasis that the existing models data places on meeting required regulatory standards, complying with ethical expectations and sourcing external research funding suggests that the top-down centralised model is preferred whenever there are open targets.

\section{Lateral targets}

Even at universities where centralised supports have been established to ensure that such open targets could be achieved, a number of participants noted that adequate attention was often not paid to the less obvious, yet equally important skills that must be developed to ensure that these clear and obvious objectives are met. These less obvious, but necessary skills, or lateral targets, materialised within the data in a variety forms. With regard to the acquisition of research funding, for example, one respondent pointed out that "the support for research is disconnected. It is focused solely on helping scholars seek funding and write better funding applications, not on other ways of developing scholars' research competences." This implies that there are additional research skills which must be honed to increase one's chances of securing research funding. Another $M C$ identified writing itself as a lateral target. As they explain, "I see this writing closely related to research. Not all academics have good writing skills, which is a shame as they miss opportunities to publish work because of this limitation. So courses need to be offered in this regard, together with good mentorship." However, the existing models data also demonstrated that some universities recognised the important affiliations between these kinds of open and lateral targets and devised a more structured and holistic approach to the matter of acquiring research funding: "Centralised support for research comprises (1) a project department which assists teachers (and to some extent students) to write projects, (2) allocation of university grants, (3) support for publications and participation in conferences, (4) workshops and seminars on project management and research methods." Indeed, at one institution where there are no centralised supports for teaching or learning, some academics seem to have addressed this gap by independently organising events that are designed to help them develop the lateral skills that are required to ensure that open targets can be achieved:

At my university, there is no centralised support for teaching. Academic teachers at some faculties organize their own methodological conferences and/or invite some leading scholars in their discipline to learn from them. The University requires that each teacher must be evaluated after each fall by students... I am not aware of any centralised support for learning at my University. There are some local initiatives, e.g. some workshops on learning skills, directed for freshmen who happen to read the information about such activities.

A representative from another institution that adopts a centralised approach to supporting research, teaching and learning which also prioritises these lateral targets notes that the "active supports" they provide "have developed strategic concepts on the further development of their topics and have successfully acquired several high-profile grants to support the transfer and realisation of these concepts into practice." All of these samples suggest that there are lateral targets that should be addressed to ensure that clear and obvious objectives, pertaining to research, writing, teaching and learning, can be achieved.

\section{Hidden targets}

As noted in the previous section, some respondents felt that they were not afforded the opportunity to hone the various skills defined here as lateral targets because the university offered no support in these areas. As one respondent succinctly put it, "regarding research and writing, there is no support provided in my institution. There is no department that offers support for academia in order to develop research papers, or to write successful project proposals, and so on." Although the skills required to develop research papers and write successful projects are lateral targets, this response also offers an example of a hidden target, because the institution in question does not provide the support that would make these skills accessible to 
the respondent. These lateral and hidden targets frequently appear simultaneously because, for some respondents, the importance of these lateral targets is made conspicuous by their absence. Another MC observed that, at their institution, "learning is organized on an individual level since there is little or no support from the University. There is no support for writing. The researchers/teachers are on their own and there is a need for such a centre." Another respondent once again highlighted the disjunction between supports that are often made available for research and those made available to support writing: "We have several service centers which support research: [Name of four research centres]. Centralised support for writing: maybe diploma thesis (e.g. MA. PhD), anti-plagiarism system." These are just some examples from the existing models data which suggest that academic staff and students are not being sufficiently supported when it comes to achieving lateral targets because the importance of these skills is not formally recognised by the university.

However, this is just one of the two ways in which hidden targets materialise in the existing models data. There are also instances when universities attempted to provide centralised supports for teaching, learning, research and writing, but failed to do so in a way that was effective, at least according to the participants. One respondent offered a detailed description of how unsuccessful and counterproductive these types of hidden targets can prove to be. Although there are mechanisms in place to support teaching, learning and writing at their university, they note that a lack of "communication" has rendered these supports ineffective as many lecturers "do not appear to know that this support is available or needed, that such support can be of benefit to them." Regarding the mechanisms that are currently in place to support research at this university, the respondent identified a vagueness around "what kind of research the institution actually values" and around the functions that "the two offices linked to research" are expected to perform. Another respondent, based at a university that only provided centralised support for research, expressed similar frustrations when discussing the possibility of receiving structured and effective support for teaching, learning and writing: "As for interoperability of the supports, as it is, I find it difficult to envisage any real possibility. Contrariwise, there seems to be some kind of incompatibility with teaching and learning exigencies. Writing is very much relegated to occasional non-centralised initiatives, so I find it hard to think of interoperability." As this respondent has observed, it is difficult to envisage how interoperability between these hidden targets might function, not least because the targets themselves appear to be non-existent. However, the top-down centralisation model designed to address open targets at some of these universities can nonetheless be used as a blueprint to address lateral and hidden targets.

\section{Blended centralised supports}

The responses recorded in the desirable models data suggest that a central hub would help to synergise supports for teaching, learning, research and writing in higher education. ${ }^{3}$ However, the consensus expressed in responses to the Likert questions was that a blended centralised supports model, which encouraged collaboration between teaching and learning experts and discipline-specific practitioners, would yield the most effective results. One participant noted that "centralised assistance, offered by educationalists specialising in teaching and learning in higher education, seems...to be the best service." Another went so far as to suggest that a centralised model "would aggregate the best practices and support and equip TLRW with best methods and approaches." Others expressed concerns that a centralised model such as this would not be able to address the discipline-specific nature of the teaching, learning, researching and writing processes. As one respondent pointed out, this model

might lead to the emergence of teams of dedicated professionals that can help the students and teachers to deal with the basic technicalities of the four activities. However, to my mind, centers are likely to approach these activities on the skill level

\footnotetext{
${ }^{3}$ It is beyond the scope of this article to provide an overview of the desirable models data as my primary objective is to explore how the structures which are currently in place to effectively support research can be modified and repurposed to more effectively support writing, teaching, and learning in higher education. See Meyhöfer (2018) for a comprehensive thematic analysis and mapping of this data.
} 
and thus may happen to background disciplinary variation, which may in turn be essential, especially in the case of writing and research.

Another observed that, even within some faculties, there were often many discipline-specific variations, noting that "different Scientific fields had different needs and characteristics." Indeed, another respondent noted that "the process of having to explain the specifics of [Name of Discipline] education/teaching to a centralised office for teaching support can (at times) be frustrating and time-consuming". However, one participant identified a potential solution for this problem:

I have selected in the options above the 'blended model' because I think that a centralised model is crucial, but it needs to take into account departmental and disciplinary issues. My ideal model would be a university centre (with dedicated staff) with 'fellows' in each department, who can play a role as liaison between the centre and local needs related to disciplines.

\section{Discussion}

The blended model that emerges as the most functional option from the responses recorded in the desirable models data is such that it lends itself to the management strengths that writing centre directors have honed as collaborative learning practitioners. These management strengths also place writing centre directors in a strong position to address the apparent schisms between the open, lateral, and hidden targets that emerged from the existing models data. As Ted Panitz (1999) explains, collaborative learning (CL) is

a personal philosophy, not just a classroom technique. In all situations where people come together in groups, it suggests a way of dealing with people which respects and highlights individual group members' abilities and contributions. There is a sharing of authority and acceptance of responsibility among group members for the groups' actions. The underlying premise of collaborative learning is based upon consensus building through cooperation by group members, in contrast to competition in which individuals best other group members. CL practitioners apply this philosophy in the classroom, at committee meetings, with community groups, within their families and generally as a way of living with and dealing with other people. (pp. 3-4)

This definition closely corresponds with the skill set that one respondent describes in the desirable models data:

people working in centralised support need to have very special qualifications. They need to be experts in (either teaching, or learning, or research, or writing), but also need to be experts in listening and communicating. They need to be able to find a balance between the demands of stakeholders and the expert knowledge they bring to it. They also need to balance permanently between service and being academic and research-based. They need to balance between administration and academia. They need to balance experts with very high social skills.

The experience that writing centre directors typically acquire when organising discipline-specific and interdisciplinary writing workshops, gathering discipline-specific writing resources and interdisciplinary learning materials, and scheduling topic-specific sessions also puts them in strong position to organise the kinds of interdisciplinary and collaborative workshops that were identified as effective in the existing models data. As Bonnie Devet (2018) has observed, writing centres encourage writing transfer, i.e., the application of writing processes to different types of writing projects. Studies have also acknowledged the success of various group activities organised by writing centres. Nzekwe-Excel (2014), for example, has identified correlations between student attendance at academic writing workshops and improved academic performance. It is possible to use the workshops and events organised by writing centres as a blueprint for research clusters, teaching workshops, topic-specific learning sessions, etc. 
Studies have shown that these kinds of active learning groups (ALGs) have proved effective for early career researchers (ECRs) (Regan \& Besemer 2009; Pyhältö et al. 2009).

Indeed, ALGs promote many of the skills and values identified as keys to academic success by senior academics because they promote important skills and values, such as inclusivity, wellbeing, interdisciplinary collaboration, creativity and innovation, communication, and digital literacy and awareness (Carmody 2019). It is difficult to determine whether the seminars and workshops identified in the existing models data function as ALGs, as there are no specific details provided about the tasks that are performed at these sessions. However, it is certainly plausible that writing centre directors could design ALGs to address many of the lateral targets that emerged from the existing models data.

An evolved version of the writing centre which is designed to function as a blended centralised supports hub for teaching, learning, research and writing could even make crucial steps towards addressing many of the hidden targets that emerged in the existing models data. Referring to challenges that materialise as a result of these hidden targets, one respondent stressed the importance of visibility in the desirable models data:

I would try to build a physical room, a space at the campus visible for everyone. A coworking-space. Within this coworking-space, there would be a real co-working area in the middle and then space dedicated to each four areas around this. For example, there would be the writing center, the learning center, the teaching center, and the center for research support around a large area for students teachers and researchers to work on their projects individually or in groups. This space would be designed to enhance exchange and creativity, but also allow solitude and quietness.

A blended centralised supports hub that maintained an online presence, via an online learning platform, could also address a number of the targets that remain hidden due to a lack of communication. As one respondent explained in the desirable models data, "I would first attempt to introduce a tool to enhance communication among departments. This would be a regular meeting for those individuals within the departments that are responsible for overseeing the four key activities in each department." The desirable models data further suggests that such a hub might increase the visibility of the opportunities that remain as hidden targets, at least for some, because they are offered informally by altruistic colleagues. Another respondent stressed the importance of creating "a core group to identify what were the practices already used in my institution; these practices could be formal or informal, since sometimes institutions already had some people dealing with this stuff in an informal way." Another noted that,

In general, there is no interoperability among these different fields of support, although in reality many activities take place to enhance teaching, learning, research and writing. The younger generation of teaching/researching staff recognizes the need for different forms of support and there is the need for suchlike services as the workshops, seminars and one-to-one consultations are attended on a regular basis.

In addition to bringing the hidden targets that emerged in the existing data more sharply into focus, then, it appears that a blended centralised supports hub which evolved from the current writing centre model could also boost the interoperability of the informal supports for teaching, learning, research and writing described in the existing models data.

\section{Conclusion}

The values and ethos associated with the learner-centred writing centre model could be echoed in a blended centralised support model for staff across teaching, learning, research and writing in higher education. Indeed, the key action-orientated insight that emerged from the COST Action data, that of the coexistence of open, lateral and hidden targets, suggests that some blend of existing and desirable supports would serve individuals, institutions and the sector well. In the case of individuals, it seems that for as long as altruistic colleagues provide these supports informally, there will inevitably be students and early career researchers (ECRs) who 
cannot avail of these opportunities because they are not aware of their existence. From the perspective of the institution, the data suggests that the formal support structures which have been implemented to ensure that open targets can be attained are generally effective; however, the data also indicates that these structures could be adapted and repurposed to ensure that lateral targets are addressed and to heighten the visibility and effectiveness of hidden targets. From the point of view of the sector, a more formalised way of addressing lateral and hidden targets, and indeed open targets in universities where these clear and obvious objectives are not formally addressed, would allow institutions to more closely tailor the supports they offer to align with the available resources and to meet the national requirements. All of these matters need to be considered when exploring what model may or may not work at a given institution; however, the most clear and irrefutable point that emerged from the data is that there is great value in asking colleagues about what exists and what might be desirable, and building a model collaboratively.

\section{Acknowledgements}

This publication is based upon collaborative work by COST Action 15221 Management Committee members, supported by COST (European Cooperation in Science and Technology). It was developed from work completed during a Short Term Scientific Mission (STSM), as part of COST Action 15221, and as supported by COST. I would also like to thank the editors and my anonymous reviewers for their very helpful comments and suggestions. 


\section{References}

Carmody, A. (2019). Thematic analysis of focus group data in order to understand and map excellence in teaching, learning, research and writing at higher education: Report of Short Term Scientific Mission COST Action 15221. Maynooth: COST Action 15221. http://www.werelate.eu/wp-content/uploads/2019/11/Carmody-STSM-report-.pdf

COST Action 15221. (2016). We ReLaTe: About and Partners. WeReLaTe. http://www.werelate.eu/about-us/

Devet, B. (2018). How tutors of academic writing can use the theory of transfer of learning. Journal of Academic Writing, 8(2), 191-201. https://doi.org/10.18552/joaw.v8i2.437

Farrell, A., O'Sullivan, I., \& Tighe-Mooney, S. (2015). An introduction to higher education writing centres. All Ireland Society for Higher Education/Irish Network for the Enhancement of Writing.

Farrell, A. (2018). Thematic analysis and mapping of existing centralised models which aim to support teaching, learning, research and writing in higher education: Report of Short Term Scientific Mission COST Action 15221. COST Action 15221. https://drive.google.com/file/d/1Gflok-RVOdfilvtRWC1WFheBNiv3zKnn/view

Fogarty, M., Kerrigan, P., O'Brien, S., \& Farrell, A. (2019). 'I can't go on, I'll go on': Liminality in undergraduate writing. In L. A. Kassner \& E. Wardle (Eds.), (Re)considering what we know: Learning thresholds in writing, composition, rhetoric, and literacy (pp. 261-278). Utah State University Press \& University Press of Colorado.

Girgensohn, K. (2018). Collaborative learning as leadership tool: The institutional work of writing centre directors. Journal of Academic Writing, 8(2), 11-23. https://doi.org/10.18552/joaw.v8i2.472

Larsson, J., \& Holström, I. (2007). Phenomenographic or phenomenological analysis: Does it matter? Examples from a study on anaesthesiologists' work. International Journal of Qualitative Studies on Health and Well-being, 2(1), 55-64. https://doi.org/10.1080/17482620601068105

Lerner, N. (2003). Punishment and possibilities: Representing writing centres: 1939-1970. Comparative Studies, 31(2), 53-72.

Meyhöfer, F. (2018). Towards a common understanding of the desirable functions of higher education centralised support for teaching, learning, research and writing: Report of Short Term Scientific Mission COST Action 15221. Maynooth: COST Action 15221. http://www.werelate.eu/wp-content/uploads/2018/11/Meyhoefer-Report-Feb2018STSM.pdf

Nzekwe-Excel, C. (2014). Academic writing workshops: Impact of attendance on performance. Journal of Academic Writing, 4(1), 12-25. https://doi.org/10.18552/joaw.v4i1.139

Panitz, T. (1999). Collaborative versus cooperative learning-A comparison of the two concepts. http://files.eric.ed.gov/fulltext/ED448443.pdf

Pyhältö, K., Stubb, J., \& Lonka, K. (2009). Developing scholarly communities as learning environments for doctoral students. International Journal for Academic Development, 14(3), 221-232. https://doi.org/10.1080/13601440903106551

Regan, J., \& Besemer, K. (2009). Using action learning to support doctoral students to develop their teaching practice. International Journal for Academic Development, 14(3), 209220. https://doi.org/10.1080/13601440903106536 